\title{
A data mining approach to improve multiple regression models of soil nitrate concentration predictions in Quercus rotundifolia montados (Portugal)
}

\author{
Jorge Nunes • Manuel Madeira • Luíz Gazarini • \\ José Neves $\cdot$ Henrique Vicente
}

Received: 23 September 2010/ Accepted: 4 July 2011/Published online: 28 July 2011

(C) Springer Science+Business Media B.V. 2011

\begin{abstract}
The changes in the soil nitrate concentration were studied during 2 years in a "montado" ecosystem, in the South of Portugal. Total rainfall, air and soil temperature and soil water content under and outside Quercus rotundifolia canopy were also evaluated. A cluster analysis was carried out using climatic and microclimatic parameters in order to maximize the intraclass similarity and minimize the interclass similarity. It was used the k-Means Clustering Method. Several cluster models were developed using $\mathrm{k}$ values ranging between 2 and 5. Thereafter, in each cluster, the data were divided according to their origin (soil under canopy and open areas, and from surface and deep layers). Multiple regression models were tested for each cluster, to assess the relationship
\end{abstract}

J. Nunes $(\bowtie)$

Institute of Mediterranean Agricultural

and Environmental Sciences, University of Évora,

Rua Romão Ramalho no 59, 7000-671 Evora, Portugal

e-mail: jdnunes@uevora.pt

\section{Madeira}

Instituto Superior de Agronomia, Universidade Técnica de Lisboa, Tapada da Ajuda, 1349-017 Lisbon, Portugal

e-mail: mavmadeira@isa.utl.pt

\section{Gazarini}

Department of Biology and Institute of Mediterranean

Agricultural and Environmental Sciences,

University of Évora, PO Box 94,

7002-554 Evora, Portugal

e-mail: gazarini@uevora.pt between soil nitrate concentration and a set of climatic and microclimatic parameters and the results were compared with models assessed without clustering. The models achieved with data grouped in result of clustering analysis showed better performance than the models achieved without clustering, mostly for data from open areas soils. When temperature is low and/or water presents excess or scarcity levels, the data from soils in undercanopy areas, give rise to models with worst performance than models from open soil areas data. The results obtained for undercanopy area suggest that nitrification process in soil under Quercus rotundifolia trees influence is more complex than for open areas, and subject to other relevant factors beyond water and temperature.

\footnotetext{
J. Neves

Department of Informatics, University of Minho,

Braga, Portugal

e-mail: jneves@di.uminho.pt

H. Vicente

Department of Chemistry and Chemistry Centre of Évora, University of Évora, Rua Romão Ramalho no 59, 7000-671 Evora, Portugal

e-mail: hvicente@uevora.pt
} 